\title{
Reformasi Sekolah melalui Lesson Study untuk Membangun Learning Community Menuju Pembelajaran Abad 21 di SD Negeri 6 Kuta Blang
}

\author{
Misnar, Asrul Karim \\ Universitas Al Muslim \\ Email: miss.saiful@gmail.com, asrulkarimpgsd@gmail.com \\ http://dx.doi.org/10.32672/btm.v1i3.1507
}

\begin{abstract}
Abstrak
Bireuen Regency needs various supports from various parties both material and moral. During the learning that took place at SD Negeri 6 Kuta Blang, the teacher was less willing to observed by other teachers. Teachers are also not ready to accept criticism from others so that the attitude to be together with others (a way of life that is related) was still not implemented in the education system. The relationship between teachers in schools and even in classrooms had not yet materialized. The learning atmosphere that was runned in the class was still less able to compete with other students, besides that there was still needed to improve the quality of educators in learning. The learning model applied by the teacher did not fully support collaborative learning. Meanwhile, there are some teachers who have implemented small groups but the purpose of learning using collaborative has not been successful. This was because lack of the teacher ability in collaborative learning. In addition, not all the teachers got the chance to attend the training related to increase the learning. Disruption of information creates a sense of injustice and trust towards fellow teachers. Circumstances like this were also increasingly creating disharmony and are not mutually related to both fellow teachers and even the principal. These things were an educational phenomenon that was happening right now in the learning process at Elementary School 6 Kuta Blang. By presenting school reforms that are based on lesson studies have produced significant results both from the learning process that involves collaborative learning that was student-centered and collegiality at school that can form a learning community based on listening to pedagogy.
\end{abstract}

Keywords: School reform, lesson study, learning community

\begin{abstract}
Abstrak
Kabupaten Bireuen membutuhkan berbagai dukungan dari berbagai pihak baik itu secara moril maupun materiil. Selama ini pembelajaran yang terjadi di SD Negeri 6 Kuta Blang, kurangnya keterbukaan guru untuk bersedia membuka kelas kepada sesama guru yang lain sehingga tidak terciptanya kolegalitas sesama para pendidik. Para guru juga belum siap untuk menerima kritikan dari orang lain sehingga sikap untuk bisa bersama-sama dengan orang lain ( $a$ way of assosiated living) masih belum dijalankan dalam sistem pendidikan. Hubungan
\end{abstract}


Misnar, Asrul Karim

untuk saling mendengarkan antar sesama guru di sekolah bahkan di ruang kelas belum terwujud. Suasana pembelajaran yang dijalankan pada saat ini para peserta didik masih kurang mampu bersaing dengan siswa lain, selain itu masih diperlukan peningkatan mutu pendidik dalam pembelajaran. Model pembelajaran yang diterapkan oleh guru belum sepenuhnya secara collaborative learning walaupun ada sebagian guru sudah menerapkan dalam kelompok-kelompok kecil tetapi tujuan dari pembelajaran yang bersifat kolaboratif belum tercapai. Hal ini dikarenakan kurangnya pengetahuan guru terhadap pembelajaran yang bersifat collaborative learning. Selain itu, tidak meratanya para guru untuk mengikuti berbagai pelatihan pembelajaran dan ada sebagian guru yang sudah mengikuti pelatihan tidak mensosialisasikan kembali kepada guru-guru yang lain. Terputusnya informasi terciptanya rasa ketidakadilan dan kepercayaan terhadap sesama guru. Keadaan seperti ini juga semakin terciptanya ketidakharmonisan dan tidak saling menghargai baik sesama guru bahkan kepada kepada kepala sekolah. Hal-hal ini merupakan fenoma pendidikan yang terjadi saat ini dalam proses pembelajaran di Sekolah Dasar Negeri 6 Kuta Blang. Dengan adanya reformasi sekolah yang berbasis lesson study telah menunjukkan hasil yang siknifikan baik dari proses pembelajaran yang bersifat collaborative learning yang berpusat pada peserta didik maupun kolegalitas disekolah yang dapat membentuk learning community berdasarkan listening pedagogy.

Kata kunci: Reformasi Sekolah, Lesson Study, Learning Community

\section{PENDAHULUAN}

Sistem pendidikan di Aceh mengacu pada Qanun provinsi Nanggroe Aceh Darussalam nomor 23 tahun 2002 tentang penyelenggaraan pendidikan di Aceh sebagaimana yang tercantum dalam Bab satu pasal satu ayat 12 bahwa "Sistem Pendidikan Provinsi Nanggroe Aceh Darussalam adalah pendidikan yang dilaksanakan di provinsi Naggroe Aceh Darussalam berdasarkan Sistem pendidikan nasional yang disesuaikan dengan nilai-nilai sosial budaya daerah serta tidak bertentangan syariat Islam. Berdasarkan qanun tersebut reformasi sekolah yang merupakan hal baru untuk diterapkan di Aceh khususnya di Kabupaten Bireuen membutuhkan berbagai dukungan dari berbagai pihak baik itu secara moril maupun materiil. Selama ini pembelajaran yang terjadi di SD Negeri 6 Kuta Blang, kurangnya keterbukaan guru untuk bersedia membuka kelas kepada sesama guru yang lain sehingga tidak terciptanya kolegalitas sesama para pendidik. Para guru juga belum siap untuk menerima kritikan dari orang lain sehingga sikap untuk bisa bersama-sama dengan orang lain ( $a$ way of assosiated living) masih belum dijalankan dalam sistem pendidikan. Hubungan untuk saling mendengarkan antar sesama guru di sekolah bahkan di ruang kelas belum terwujud. Suasana pembelajaran yang dijalankan pada saat ini para peserta didik masih kurang mampu bersaing dengan siswa lain, selain itu masih diperlukan peningkatan mutu pendidik dalam pembelajaran. Model pembelajaran yang diterapkan oleh guru belum sepenuhnya secara collaborative learning walaupun ada sebagian guru sudah menerapkan dalam kelompok-kelompok kecil tetapi tujuan dari pembelajaran yang bersifat kolaboratif belum tercapai. Hal ini dikarenakan kurangnya pengetahuan guru terhadap pembelajaran yang bersifat collaborative learning. Selain itu, tidak meratanya 
BAKTIMAS

Jurnal Pengabdian pada Masyarakat
Vol. 1, No. 3,

Oktober 2019
eISSN 2685-113x

pISSN 2685-0303

para guru untuk mengikuti berbagai pelatihan pembelajaran dan ada sebagian guru yang sudah mengikuti pelatihan tidak mensosialisasikan kembali kepada guru-guru yang lain. Terputusnya informasi terciptanya rasa ketidakadilan dan kepercayaan terhadap sesama guru. Keadaan seperti ini juga semakin terciptanya ketidakharmonisan dan tidak saling menghargai baik sesama guru bahkan kepada kepada kepala sekolah. Hal-hal ini merupakan fenoma pendidikan yang terjadi saat ini dalam proses pembelajaran di Sekolah Dasar Negeri 6 Kuta Blang.Berdasarkan hasil anaslisis masalah yang dialami oleh guru SD Negeri 6 Kua Blang, membutuhkan penangan lebih lanjut agar tidak berimbas kepada kondisi pembelajaran yang dilakukan guru dikemudian hari.

Potret kompetensi guru SD/MI di provinsi aceh juga belum menggembirakan. Nilai Ujian Kompetensi Guru Aceh masih rendah. Menurut Laisani selaku Kepala Dinas Pendidikan Aceh pada situs http://aceh.tribunnews.com/2018/03/09/peringkatuji-kompetensi-guru-di-aceh-naik-ke-ranking-15-nasional bahwa pada tahun 2015 peringkat UKG aceh berada pada posisi nomor 3 terendah secara nasional. Pada tahun 2016 berada pada peringkatkan 23 nasional dan pada tahun 2017 berada pada perangkat 15 nasional. Berdasarkan keadaan tersebut reformasi sekolah menjadi solusi tepat sebagai pembinaan guru melalui lesson study untuk membangun komunitas belajar di lingkungan sekolah. Berdasarkan pengalaman yang telah dilakukan oleh salah satu tokoh lesson study di Jepang yaitu Manabu Sato yang juga merupakan dosen di Univeritas Tokyo dalam bukunya "Reformasi Sekolah (Konsep dan Praktik Komunitas Belajar) telah melakukan reformasi sekolah di Jepang dengan beberapa sekolah model (pilot school) di Jepang dalam pengembangan Learning Community antara lain SD Negeri Ojiwa provinsi Nigata pada tahu 1995, SD Hamanogo di Cigasaki pada tahun 1998, SMP Minami Di Nagaoka pada tahun 1997, SMP Gakuyo di provinsi Fuji, Shizuoka pada tahun 2001, SMA Anzai di Hiroshima pada tahun 2005 dan SMA Negeri Numazu di Johoku, Shizuoka pada tahun 2005. Sejak tahun 2000 reformasi sekolah dengan komunitas belajar telah menyebar luas di luar Jepang melalui buku, jurnal yang kemudian diperkenalkan ke negara-negara lain termasuk Indonesia melalui program IMSTEP JICA pada tahun 2001 yang terus berkembang sampai program STOLS-ITTEP.

Beberapa hasil penelitian juga menemukan bahwa dengan pelaksanaan lesson study sangat membantu guru dalam meningkatkan kualitas pembelajaran. Seperti temuan Rusman (2010: 205) lesson study salah satu upaya untuk meningkatkan proses dan hasil pembelajaran yang dilaksanakan secara kolaboratif dan berkelanjutan oleh sekelompok guru. Dengan tujuan (1) memperoleh pemahaman yang lebih baik tentang bagaimana siswa belajar dan guru mengajar; (2) memperoleh hasil tertentu yang bermanfaat bagi para guru yang lainnya dalam pelaksanaan pembelajaran; (3) meningkatkan pembelajaran secara sistematis melalui inkuiri kolaboratif; (4) membangun sebuah pengetahuan pedagogis, di mana seorang guru dapat menimba pengetahuan dari guru lain. Herman (2012: 57) menyatakan bahwa dalam lesson study tidak hanya guru yang melaksanakan pembelajaran yang dapat memetik manfaat, namun para observer (guru lain/mitra, mahasiswa, dosen dan pihak-pihak lain) yang hadir pada saat pembelajaran. Dengan mengamati kegiatan pembelajaran yang dilakukan seorang guru, observer didorong untuk merefleksikan pembelajaran yang 
Misnar, Asrul Karim

dilaksanakannya dan bagaimana meningkatkan kualitasnya. Oleh karena itu, lesson study sesungguhnya merupakan forum belajar bersama untuk saling belajar dari pengalaman guna meningkatkan kualitas pembelajaran.

\section{METODE}

Adapun metode pelaksanaan untuk mengatasi permasalahan pada PKM "Reformasi Sekolah Melalui Lesson Study Untuk Membangun Learning Community Menuju Pembelajaran Abad 21 Di SD Negeri 6 Kuta Blang" ini terdiri dari 5 kegiatan mulai dari identifikasi dan analisis masalah yang dialami oleh guru di SD Negeri 6 Kuta Blang, menyelenggarakan workshop tentang lesson study, merancang perangkat pembelajaran, simulasi lesson study open class kegiatan lesson study, melakukan pendampingan dan evaluasi. Berikut ini akan di deskripsikan rangkaian kegiatan PKM "Reformasi Sekolah Melalui Lesson Study Untuk Membangun Learning Community Menuju Pembelajaran Abad 21 Di SD Negeri 6 Kuta Blang”.

1. Melaksanakan workshop lesson study

Adapun kegiatan yang dilakukan untuk mengatasi permasalah mitra akan di laksanakan kegiatan workshop atau pelatihan dengan tema sebagai berikut:

a. Tema 1: Lesson study dan visi dan filiosofi komunitas belajar

b. Tema 2: Reformasi sekolah dengan pembelajaran kolaboratif

c. Tema 3: Pembentukan kolegalitas diantara guru dan model pembelajaran kolaboratif

d. Tema 4: Merancang pembelajaran kolaboratif

e. Tema 5: Meningkatkan aktivitas siswa dalam pembelajaran kolaboratif

2. Merancang perangkat pembelajaran

Pada tahap ini guru-guru merancang pembelajaran secara bersama, mulai dari menganalis kurikulum, materi, kebutuhan siswa, kemampuan materi prasayarat hingga merancang RPP, LKS, dan evaluasi. Pada tahap ini diharapkan terbentuknya kolegalitas diantara guru dis SD Negeri 6 Kuta Blang.

3. Simulasi lesson study open class kegiatan lesson study

Setelah guru-guru menyusun perangkat pembelajaran, guru melakukan simulasi lesson study. Pada saat simulasi salah satu guru menjadi guru model dan yang lainnya sebagai siswa model. Pada kegiatan simulasi ini memberikan pengalaman nyata kepada tentang lesson study. Dengan Kegiatan simulasi, guru memperoleh pengalaman dan umpan balik terhadap pembelajaran dengan Lesson study yang mereka lakukan pada saat simulasi berlangsung.

4. Open Class (Penerapan Lesson Study)

Pada tahap ini apa yang sudah dirancang dan direncanakan diterapkan dikelas

5. Melakukan pendampingan dan evaluasi

Pendampingan dilakukan oleh tim PKM terhadap guru dilakukan agar pengetahuan yang di dapat pada saat mengikuti kegiatan workshop dansimulasi, serta open class dapat dilanjutkan sehingga pada nantinya guru-guru SD Negeri 6 Kuta Blang dapat mandiri dalam menerapkan lesson Study sehingga terbentuknya kolegalitas antar guru.

6. Penerapan secara berkelanjutan. 
BAKTIMAS

Jurnal Pengabdian pada Masyarakat
Vol. 1, No. 3,

Oktober 2019
eISSN 2685-113x

pISSN 2685-0303

Walaupun pada nantinya program hibah ini berakhir maka tim PKM, guru dan kepala sekolah SD akan melanjutkan serta menerapkan lesson study sehingga apa yang tercapai apa yang sudah rencanakan sebelumnya yaitu Membangun Learning Community Menuju Pembelajaran Abad 21 Di SD Negeri 6 Kuta Blang.

Berikut ini disajikan tahapan dari metode palaksanaan kegiatan PKM "Reformasi Sekolah Melalui Lesson Study Untuk Membangun Learning Community Menuju Pembelajaran Abad 21 Di SD Negeri 6 Kuta Blang.

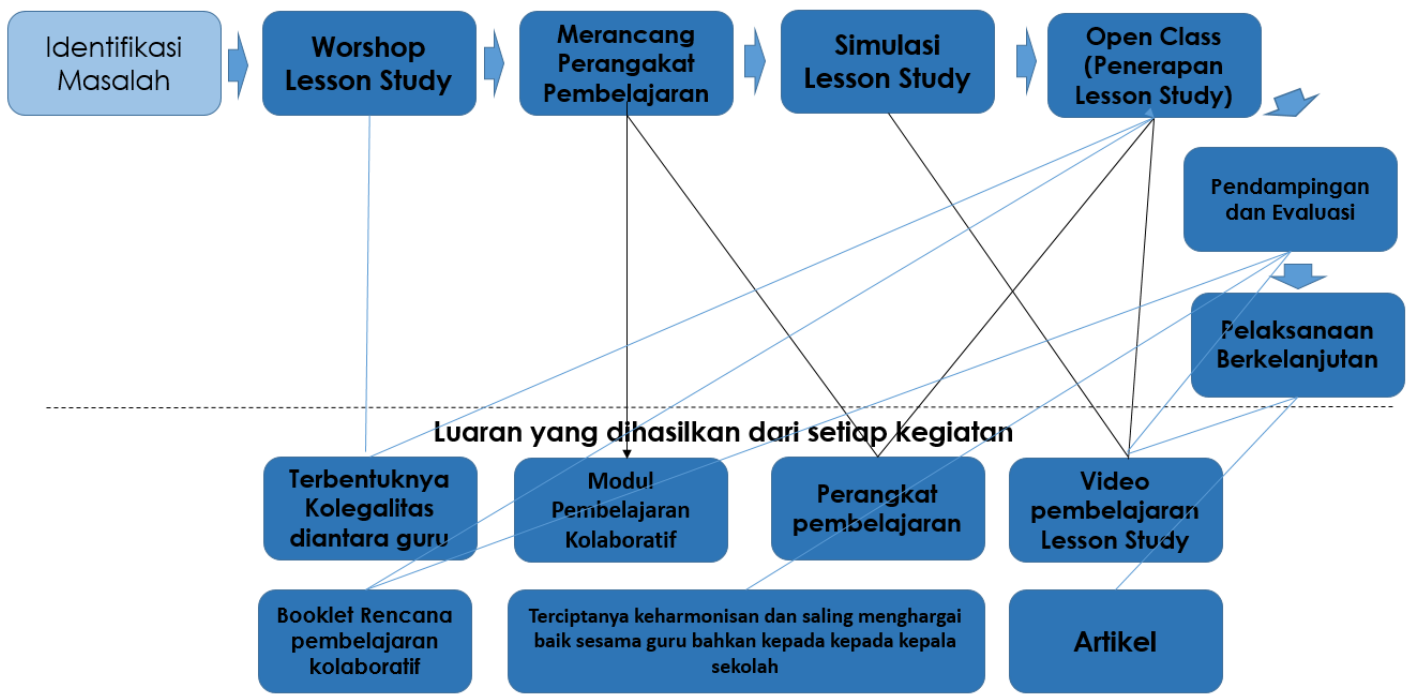

Gambar 1. Metode palaksanaan kegiatan PKM "Reformasi Sekolah Melalui Lesson Study Untuk Membangun Learning Community Menuju Pembelajaran Abad 21 Di SD Negeri 6 Kuta Blang.

\section{HASIL DAN PEMBAHASAN}

Adapun aoutput yang telah dihasilkan dari Program Kemitraan Masyarakat (PKM) ini antara lain perangkat pembelajaran yang telah disusun oleh guru yang terdiri dari 2 tim yaitu tim guru IPA dengan pelaksanaan pembelajaran pada kelas IV dan tim Matematika dengan pelaksanaan pada kelas V. Hasil perangkat pembelajaran yang telah disusun berjumlah 33 perangkat yang berbasis lesson study dengan menitikberatkan pada pembelajaran collaborative learning. Sebagai bukti pendukung dari praktik pembelajaran telah dihasilkan berupa video pembelajaran.

Dibawah ini dijelaskan secara rinci tahapan dan output yang gtelah dicapai dari program kegiatan pengabdian di sekolah SD Negeri 6 Kuta Blang.

\section{Workshop Lesson Study}

Kegiatan pertama yang dilakukan dalam program pengabdian ini adalah dilakukannya workshop penguatan dan pemahaman tentang lesson study yang dilaksanakan di sekolah selama 2 hari. Pada tahap ini dijelaskan tentang apa dan mengapa lesson study itu perlu untuk dilakukan dalam pembelajaran. selain itu, inti dari workshop ini guru dapat memahami pentingnya peran semua pihak tidak hanya guru bahkan kepala sekolah, staf administrasi para orang tua murid dalam mewujudkan 
Misnar, Asrul Karim

reformasi sekolah. Hal ini dikarenakan sebuah perubahan tidak bisa dilakukan oleh satu pihak saja akan tetapi semua pihak yang terlibat dalam pelaksanaan pendidikan mempunyai peran penting untuk dapat memberikan warna dalam pembelajaran yang dimulai dari menerima keadaan peserta didik apa adanya mereka.

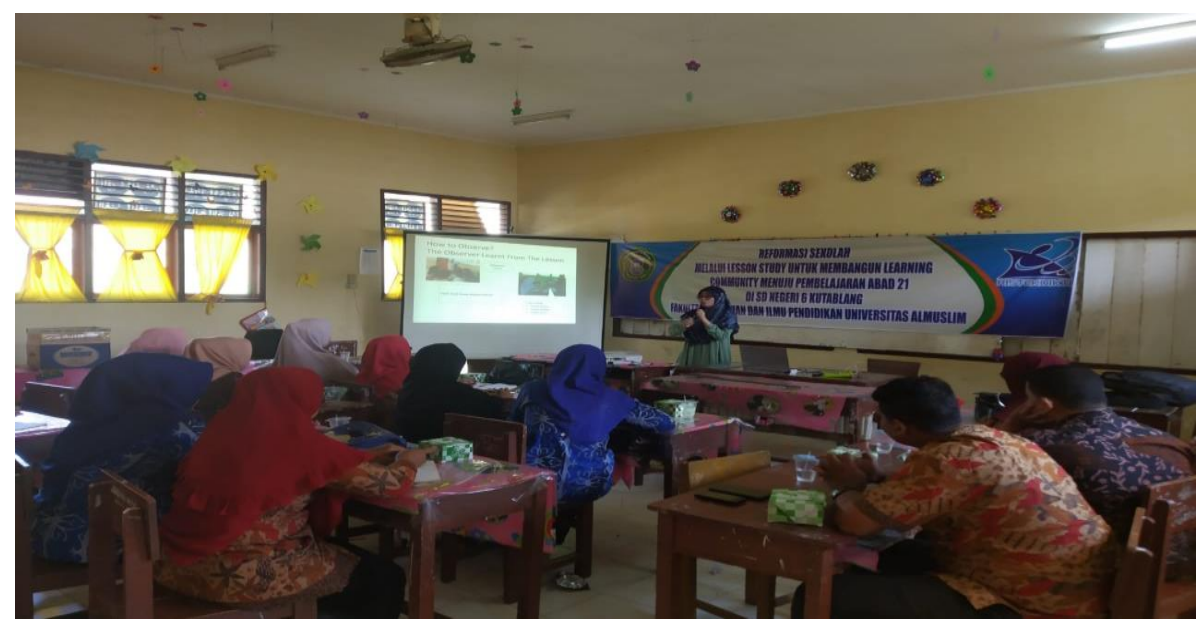

Gambar 1. Workshop Lesson Study

\section{Workshop Merancang Perangkat Pembelajaran berbasis Lesson Study}

Adapun kegiatan kedua dari program ini adalah menyusun perangkat pembelajaran sesuai dengan tim yang telah dibagi yaitu Tim IPA dan Tim Matematika. Kedua tim ini bersama-sama merancang pembelajaran dengan menganalisis kebutuhan siswa yang berbasis collaborative learning. Tujuan dari workshop ini agar skenario pembelajaran yang menjadi pedoman untuk diajarkan kepada peserta didik dapat berjalan dengan baik yang dimulai dari listening pedagogic dimana para guru bisa saling asah asih asuh dan dapat membentuk komunitas belajar dan saling membelajarkan. Hasil dari kegaiatan ini yaitu perangkat pembelajaran berbasis lesson study.

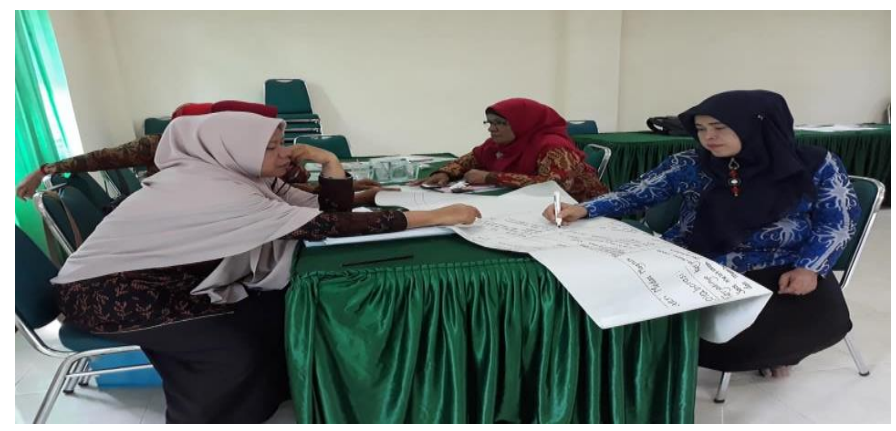

Gambar 2. Workshop Merancang Perangkat Pembelajaran berbasis Lesson Study Kelompok I 
BAKTIMAS

Jurnal Pengabdian pada Masyarakat
Vol. 1, No. 3,

Oktober 2019
eISSN 2685-113x

pISSN 2685-0303

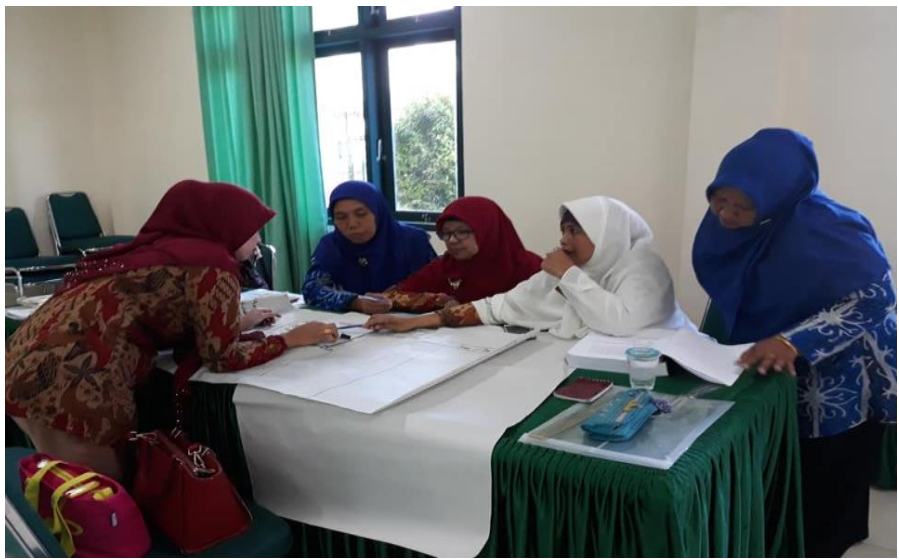

Gambar 3. Workshop Merancang Perangkat Pembelajaran berbasis Lesson Study Kelompok II

\section{Praktik pembelajaran}

Tahap ketiga yang telah dilakukan yaitu praktik pembelajaran sesuai dengan skenario pembelajaran yang telah disusun pada workshop perangkat pembelajaran oleh guru model. Pada saat praktik mengajar guru model membuka kelasnya untuk umum agar guru yang lain dapat mengobservasi proses pembelajaran dan aktivitas peserta. Para observer diberikan lembar observasi untuk mencatat semua aktivitas yang telah berlangsung. Berdasarkan hasil tersebut para observer dan guru model melakukan refleksi sebagai tahap saling berbagi dan memberikan masukan untuk perbaikan pembelajaran selanjutnya.
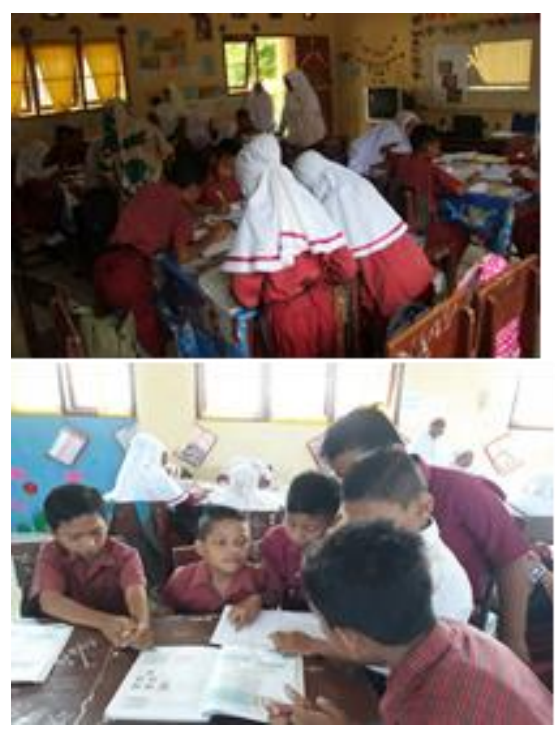

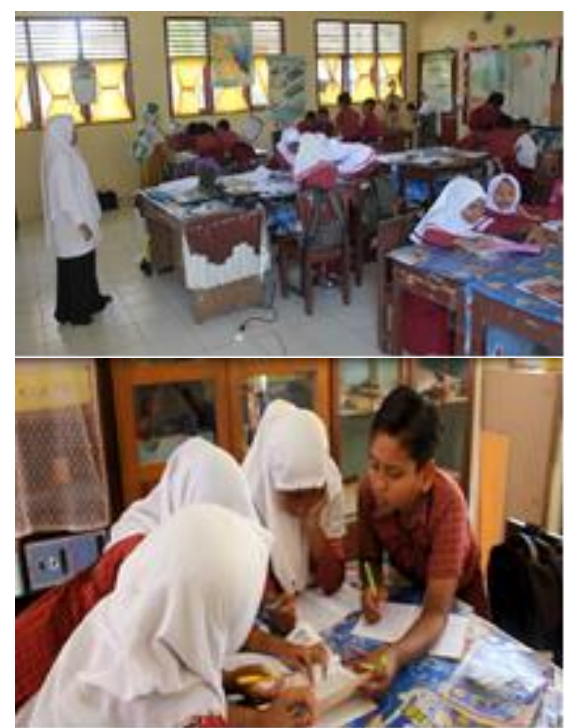

Gambar 3. Aktivitas Siswa, Guru Model, serta Observer Pada Praktik Pembelajaran 
Misnar, Asrul Karim

\section{PENUTUP}

Lesson study merupakan pendekatan untuk meningkatkan mutu pembelajaran yang dilakukan oleh guru secara kolaboratif melalui beberapa tahapan yang dimulai dari merancang pembelajaran (lesson design) untuk mencapai tujuan pembelajaran, mengamati pelaksanaan proses pembelajaran oleh observer serta melakukan refleksi untuk untuk mendiskusikan hasil proses pembelajaran yang dikaji untuk mendapatkan penyempurnaan dalam pelaksanaan pembelajaran berikutnya.

Dengan adanya kegiatan PKM untuk pendampingan sekolah yang berbasis lesson study untuk melakukan reformasi sekolah diharapkan adanya saling kerjasama dan menghargai menuju perubahan pembelajaran yang difokuskan pada aktivitas siswa dengan anggapan bahwa dengan adanya perubahan dan peningkatan aktivitas siswa maka akan adanya perubahan juga terkait aktivitas guru selama mengajar dikelas.

\section{DAFTAR PUSTAKA}

Herman. 2012. Meningkatkan Kualitas Pembelajaran Matematika Sekolah Dasar Melalui Lesson Study. Jurnal Pendidikan , Volume 13, Nomor 1, Maret 2012. [Online] http://jurnal.ut.ac.id/index.php/JP/article/download/152/122/

Jasmaniah, Karim. A, Zulkifli. 2013. Implementasi Pembelajaran Bilangan dan Operasinya Melalui Lesson Study: Pengalaman Mengimplementasikan Lesson Study. Jurnal Pendidikan Almuslim, Volume 1, Nomor 1 2013. [Online] http://jfkip.umuslim.ac.id/index.php/jupa/article/view/66.

Laisani. 2018. Peringkat Uji Kompetensi Guru di Aceh Naik ke Ranking 15 Nasional, serambinews.com, $\quad 9 \quad$ Maret $2018 . \quad$ [Online] http://aceh.tribunnews.com/2018/03/09/peringkat-uji-kompetensi-guru-di-acehnaik-ke-ranking-15-nasional.

Manabu Sato. 2012. Mereformasi Sekolah (Konsep dan Praktek Komunitas Belajar. Tokyo

Misnar. 2014. Becoming Reflective Education and Profesionals of Learning. WALS, Bandung Indonesia 